\title{
Polygonum cuspidatum inhibits pancreatic lipase activity and adipogenesis via attenuation of lipid accumulation
}

\author{
Young Sook Kim, Yun Mi Lee ${ }^{1}$, Joo Hwan Kim² and Jin Sook Kim ${ }^{1 *}$
}

\begin{abstract}
Background: Obesity causes metabolic disease and is a serious health problem around the world. Polygonum cuspidatum (POCU1b) has been used clinically for the treatment of constipation, gallstones, hepatitis, and inflammation in East Asian countries. The principal aim of this study was to investigate for the first time whether the extract of Polygonum cuspidatum (POCU) biologically affects adipogenesis in 3 T3-L1 preadipocytes.
\end{abstract}

Methods: Fractions (n-hexan, ethyl acetate, $n$-butanol, and water) of POCU ethanol extract were evaluated in vitro for their inhibitory activities on pancreatic lipase. Of the fractions, the $n$-butanol of POCU ethanol extract (POCU1b) was examined anti-obesity activity in 3 T3-L1 preadipocytes. To examine the inhibitory effect of POCU1b on adipogenesis, 3 T3-L1 preadipocytes were treated every the other day with POCU1b at various concentrations $(0 \sim 25 \mu \mathrm{g} / \mathrm{mL})$ for twelve days. Oil-red $\mathrm{O}$ staining and triglyceride content assay were performed to determine the lipid accumulation. The expression of mRNA and proteins associated lipid accumulation was measured using RT-PCR and Western blotting analysis. We also examined the effect of POCU1b on level of phosphorylated AMP-activated protein kinase (PAMPK) in 3 T3-L1 preadipocytes with POCU1b at various concentrations during adipocyte differentiation.

Results: POCU1b exhibited the most pronounced inhibitory effects on pancreatic lipase activity. We found that POCU1b inhibited adipocyte differentiation in 3 T3-L1 preadipocytes in a dose-dependent manner, as evidenced by the reduced formation of lipid droplets and decreased glycerol-3-phosphate dehydrogenase (GPDH) activity. We also showed that the expression levels of adipocyte differentiation-related protein (ADRP) and perilipin (a protein that coats lipid droplets in adipocytes) were both reduced after POCU1b treatment. Peroxisome proliferatoractivated receptor-gamma (PPAR- $\gamma$ ) and CCAAT/enhancer-binding protein-alpha (C/EBP-a) proteins, both major adipogenic transcription factors, were markedly reduced by POCU1b. Moreover, ADRP, perilipin, C/EBP-a, and PPAR- $\gamma$ mRNA levels were also reduced by POCU1b. Levels of phosphorylated AMP-activated protein kinase (PAMPK) were elevated after POCU1b treatment $(5,10$, and 25) in a dose-dependent manner.

Conclusions: Taken together, these results suggest that the anti-obesity effects of POCU1b involve the inhibition of pancreatic lipase activity and adipogenesis via the down-regulation of lipid accumulation.

Keywords: Adipocyte differentiation, Phosphorylated AMP-activated protein kinase (pAMPK), Adipocyte differentiation-related protein (ADRP), Perilipin, PPAR-gamma, C/EBP-alpha, Polygonum cuspidatum

\footnotetext{
* Correspondence: jskim@kiom.re.kr

${ }^{1}$ Korean Medicine-Based Herbal Drug Development Group, Herbal Medicine Research Division, Korea Institute of Oriental Medicine (KIOM), Daejeon 305-811, Republic of Korea

Full list of author information is available at the end of the article
} 


\section{Background}

Obesity, a common nutritional disorder, results from the disequilibrium between energy intake and expenditure. It is believed to be associated with numerous diseases, including hyperlipidemia, hypercholesterolemia, hypertension, and type 2 diabetes [1,2]. Adipocytes store excess energy in the form of triglycerides which are contained inside lipid droplets, organelles composed of a neutral lipid core surrounded by a protein-coated single phospholipid layer [3]. Both the number and size of mature adipocytes are increased compared with preadipocytes in adipose tissues, and the inhibition of adipogenesis during the maturation of preadipocytes to adipocytes regulates the amount of adipose tissue mass [4].

Natural products have the potential to inhibit adipogenesis and induce the apoptosis of mature adipocytes $[5,6]$. Herbal extracts and phytochemicals have shown anti-obesity effects, especially the downregulation of the adipogenic transcriptional factors peroxisome proliferator-activated receptor- $\gamma($ PPAR- $\gamma)$ and CCAAT/enhancer binding protein- $\alpha$ (C/EBP- $\alpha)$, the inhibition of fatty acid accumulation, and the stimulation of glycerol-3-phosphate dehydrogenase (GPDH) activity in 3 T3-L1 preadipocytes [7-10]. Berberine, a natural plant product, displays beneficial effects in the treatment of diabetes and obesity at least in part via the stimulation of AMP-activated protein kinase (AMPK) activity [11]. AMPK is an intracellular energy sensor that plays a central role in the regulation of lipid and glucose metabolism [12]. Hydroxycitric acid ( $\mathrm{HCA})$, the active ingredient in the herbal compound Garcinia cambogia, acts as an anti-obesity agent and has been used as a natural supplement for weight management [13]. Recently, newer approaches for the treatment of obesity have involved inhibition of dietary triglyceride absorption via inhibition of pancreatic lipase as this is the major source of excess calories [14]. Orlistat is the derivative of lipstatin, a potent natural inhibitor of pancreatic lipases isolated from bacterium. Orlistat promotes body weight loss and reduces the incidence of diabetes by nearly $40 \%$ in obese people [15]. However, it has serious side effects, such as steatorrhea, stomach pain, irregular menstrual periods, and headaches [16].

Polygonum cuspidatum (P. cuspidatum, Polygonaceae) has been used clinically for the treatment of constipation, gallstones, hepatitis, and inflammation in East Asian countries such as Korea, China, Taiwan, and Japan [17], little work has been carried out regarding the effects on anti-obesity. In the present study, to elucidate activities of $P$. cuspidatum on anti-obesity, we screened candidates for lipase inhibitory activity from the $P$. cuspidatum fractions and investigated the effects of butanol fraction of the ethanol extract of $P$. cuspidatum (POCU1b) on the regulation of adipocyte differentiation. Our findings suggest for the first time that POCU1b inhibits adipocyte differentiation through the attenuation of lipid accumulation.

\section{Methods}

\section{Preparation of Polygonum cuspidatum extract}

Radix of P. cuspidatum were purchased from a commercial supplier in Jung-dong, Daejeon, Korea in November 2008 and identified by Prof. J.H. Kim in the Department of Life Science, Gachon University. A voucher specimen was deposited at the Herbarium of Diabetic Complication Research Team, Korea Institute of Oriental Medicine. The dried plant material $(5.5 \mathrm{~kg})$ was extracted with ethanol $(3 \times 36 \mathrm{~L})$ by maceration at room temperature for 3 days and the extracts were concentrated in vacuo at $40^{\circ} \mathrm{C}$. The concentrated extract $(580 \mathrm{~g})$ was diluted in water $(2 \mathrm{~L})$ and then partitioned successively with $n$-hexane, ethyl acetate, $n$-butanol, and water, respectively. The percentage $(\mathrm{w} / \mathrm{w})$ yield of the lyophilized butanol fraction of the ethanol extract of P. cuspidatum (POCU1b) was $1.9 \%$. For water extract, the dried plant $(0.1 \mathrm{~kg})$ was extracted with boiling water $(3 \times 1.5 \mathrm{~L})$ and the extract was in vacuo at $40^{\circ} \mathrm{C}$. The percentage yield of water extract was $24.8 \%$.

\section{Pancreatic lipase activity of Polygonum cuspidatum extract and its fractions}

The method for measuring pancreatic lipase activity was modified from that of Kim and colleagues [18,19]. Briefly, an enzyme buffer was prepared by the addition of a solution of porcine pancreatic lipase $[2.5 \mathrm{mg} / \mathrm{ml}$ in $10 \mathrm{mM}$ MOPS (morpholinepropanesulphonic acid) and $1 \mathrm{mM}$ EDTA, pH 6.8] to $169 \mu \mathrm{l}$ of Tris buffer $(100 \mathrm{mM}$ Tris- $\mathrm{HCl}$ and $\left.5 \mathrm{mM} \mathrm{CaCl}_{2}, \mathrm{pH} 7.0\right)$. Then, either $20 \mu \mathrm{l}$ of the plant extracts and fractions at the test concentration, or orlistat, was mixed with $20 \mu \mathrm{l}$ of the enzyme buffer and incubated for $15 \mathrm{~min}$ at $37^{\circ} \mathrm{C}$ with $5 \mu$ of the substrate solution [10 mM p-NPB (p-nitrophenyl butyrate) in dimethyl formamide]. The enzymatic reactions were allowed to proceed for $30 \mathrm{~min}$ at $37^{\circ} \mathrm{C}$. Lipase activity was determined by measuring the hydrolysis of $\mathrm{p}$-NPB to p-nitrophenol at $405 \mathrm{~nm}$ using an ELISA reader (BIO-TEK, Synergy HT, VT, USA).

\section{Culture and differentiation}

The 3 T3-L1 preadipocyte cell line was purchased from the American Type Culture Collection (Rockville, MD, USA). The cells were cultured in $4.5 \mathrm{~g} / \mathrm{L}$ glucoseDMEM with $10 \%$ calf serum, penicillin $(100 \mathrm{U} / \mathrm{ml})$, and streptomycin $(100 \mu \mathrm{g} / \mathrm{ml})$ in $10-\mathrm{cm}$ plastic Petri dishes 
until they reached $100 \%$ confluence. For differentiation, 2-day post-confluent cells were incubated for $48 \mathrm{~h}$ in DMEM with $10 \%$ FBS, antibiotics, and a differentiation cocktail termed MDI, which contained $0.5 \mathrm{mM}$ isobutylmethylxanthine, $1 \mu \mathrm{M}$ dexamethasone, and $1 \mu \mathrm{g} / \mathrm{ml}$ insulin. After $48 \mathrm{~h}$, the cells were maintained in DMEM with $10 \%$ FBS, antibiotics, and $5 \mu \mathrm{g} / \mathrm{ml}$ insulin. Cells were cultured for 12 days in DMEM with $10 \%$ FBS and antibiotics, and the media changed every 2 days until the cells were collected for analysis.

\section{Cytotoxicity assay}

Cytotoxicity was evaluated in vitro by determining cell viability using the CCK-8 kit (Cell Counting Kit-8, Dojindo laboratories, Tokyo, Japan). Cells were plated at a density of $1 \times 10^{3}$ cells $/ \mathrm{ml}$ in 96-well plates and allowed to attach overnight. The cells were then treated with POCU1b $(1-200 \mu \mathrm{g} / \mathrm{ml})$ and incubated for 5 and 12 days. After a 4-h incubation with the CCK-8 solution, absorbance was measured with a microtiter plate reader (Bio-Tek, Winooski, VT, USA) at $450 \mathrm{~nm}$. We calculated the percent viability as optical density of treated sample/ optical density of untreated control $\times 100$.

\section{Oil Red $\mathrm{O}$ staining for intracellular triglycerides}

Cells were washed twice with PBS on day 12 and fixed on dishes with 3\% formaldehyde in PBS for $20 \mathrm{~min}$. After two rinses with PBS, cells were incubated with an Oil red $\mathrm{O}$ solution (0.5\% Oil red O, 60\% isopropanol, and $40 \%$ water) and filtered through a $0.22-\mu \mathrm{m}$ filter for $30 \mathrm{~min}$. The monolayer was extensively washed with water to remove unbound dye. Representative images of treated cells were obtained with an Olympus microscope (BX51, Japan), equipped with an Olympus DP 70 camera. Stained cells were air-dried overnight and then dissolved in isopropanol. Absorbance was measured at $520 \mathrm{~nm}$.

\section{Glycerol-3-phosphate dehydrogenase (GPDH) activity assay}

Treated cell lysates were extracted and used to determine GPDH activity as described [20,21]. Briefly, protein lysate was measured according to the bicinchoninic acid assay (BCA) method, and the GPDH assay was performed to assess the disappearance of NADH during the GPDH-catalyzed reduction of dihydroxyactone phosphate (DHAP) under zero-order conditions as described $[20,21]$.

\section{Immunoblotting}

Immunoblotting was performed using a previously described method [22]. Cells were homogenized in a solution containing $250 \mathrm{mM}$ sucrose, $1 \mathrm{mM}$ ethylenediaminetetraacetic acid (EDTA), $0.1 \mathrm{mM}$ phenylmethylsulfonyl fluoride
(PMSF), and $20 \mathrm{mM}$ potassium phosphate buffer (pH 7.6). Equal amounts of protein $(25-50 \mu \mathrm{g} /$ lane $)$ were subjected to immunoblotting with the indicated antibodies. The antibodies used were the following; PPAR- $\gamma$ (1:1000), adipocyte differentiation-related protein (ADRP, 1:1000), perilipin (1:1,000) from Santa Cruz Biotechnology (Santa Cruz, CA, USA); pAMPK, and C/EBP- $\alpha$ (1:1,000) from Cell Signaling (MA, USA). The bound horseradish peroxidase-conjugated secondary antibody was detected using an enhanced chemiluminescence detection system (iNtRON Biotechnology, SeongNam-Si, Korea). Protein expression levels were determined by analyzing the signals captured on the nitrocellulose membranes using an image analyzer (Las-3000, Fuji photo, Tokyo, Japan).

\section{RNA extraction and semi-quantitative RT-PCR}

Total RNA isolation and RT-PCR were performed as previously described [22]. For RT-PCR, cDNA was synthesized with $1 \mu \mathrm{g}$ RNA using RT-premix (Bioneer, Daejeon, Korea). The primers used are summarized in Table 1. QuantumRNA 18S (Ambion Inc., Austin, TX, USA) was used as an internal control. PCR products were analyzed by agarose (1.2\%) gel electrophoresis along with DNA molecular markers, stained with ethidium bromide, and visualized under UV light. The intensities of RT-PCR products in the agarose gels were quantified by densitometry (Las-3000, Fuji photo).

\section{Statistical analysis}

Data are expressed as the mean \pm S.E.M. from multiple experiments. Comparison between groups was performed using a one-way ANOVA followed by a Tukey's test (PRISM software, Graph Pad, San Diego, CA, USA).

\section{Results \\ Lipase inhibitory activity of Polygonum cuspidatum extract and fractions}

First, we evaluated in vitro the lipase inhibitory activity of natural products and P. cuspidatum was chosen for more detail investigation. Pancreatic lipase inhibition of $P$. cuspidatum extract and fractions is expressed as percentage and $\mathrm{IC}_{50}$ (Table 2). Butanol fraction of the ethanol extract of $P$. cuspidatum (POCU1b) exhibited the strongest inhibitory effect on lipase with an $\mathrm{IC}_{50}$ value of $15.8 \mu \mathrm{g} / \mathrm{ml}$. Next, we tested the effect of P. cuspidatum extract and fractions on adipocyte differentiation of 3 T3-L1 preadipocytes. POCU1b was the most effective in the prevention of adipogenesis (Additional file 1: Figure S1). Thus, we investigated the anti-obesity effects of POCU1b on adipocyte differentiation of 3 T3-L1 preadipocytes and the related molecular mechanism of lipid accumulation. 
Table 1 Sequences of primers and PCR conditions for semi-quantitative RT-PCR

\begin{tabular}{|c|c|c|c|c|}
\hline Gene & Sequence $\left(5^{\prime}-3^{\prime}\right)$ & Annealing temperature $\left({ }^{\circ} \mathrm{C}\right)$ & Size (bp) & Accession No. \\
\hline ADRP & & 55 & 352 & NM_00748 \\
\hline Sense & CTT GTG TCC TCC GCT TAT GTC AGT & & & \\
\hline Anti-sense & CTG CTC CTT TGG TCT TAT CCA CCA & & & \\
\hline Perilipin & & 55 & 508 & NM_175640 \\
\hline Sense & CTT TCT CGA CAC ACC ATG GAA ACC & & & \\
\hline Anti-sense & CCA CGT TAT CCG TAA CAC CCT TCA & & & \\
\hline PPAR- $\gamma$ & & 55 & 220 & NM_011146 \\
\hline Sense & CCA GAG CAT GGT GGG TTC GCT G & & & \\
\hline Anti-sense & GAG CTG ACC CAA TGG TTG CTG & & & \\
\hline C/EBP-a & & 55 & 238 & NM_007678 \\
\hline Sense & AGG TGG TGG AGT TGA CCA GT & & & \\
\hline Anti-sense & CAG CCT AGA GAT CCA GCG AC & & & \\
\hline
\end{tabular}

\section{Cytotoxicity assay}

Cytotoxicity assay was performed to evaluate whether POCU1b had any effects on 3 T3-L1 viability and to determine the optimal conditions required. During the differentiation processes, 3 T3-L1 preadipocytes were treated with insulin and POCU1b for 5 and 12 days (Figure 1A). There were no effects on cytotoxicity at low concentrations of POCU1b $(1,5,10$, and $25 \mu \mathrm{g} / \mathrm{ml})$ and HCA $(25 \mu \mathrm{g} / \mathrm{ml})$ (Figure 1B). However, high concentrations of POCU1b $(100$ and $200 \mu \mathrm{g} / \mathrm{ml})$ altered cell viability after
12 days (Figure $1 \mathrm{C}$ ). Hydroxycitric acid (HCA, a positive anti-obesity control) did not alter cytotoxicity after 12 days at concentrations up to $50 \mu \mathrm{g} / \mathrm{ml}$.

\section{POCU1b inhibits adipocyte differentiation and GPDH} activity

To determine the effects of POCU1b on adipogenic conversion, 3 T3-L1 preadipocytes were induced to differentiate in the presence or absence of POCU1b and stained with Oil red O. Lipid droplets in untreated control cells

Table 2 Lipase inhibitory activity of Polygonum cuspidatum fractions

\begin{tabular}{|c|c|c|c|c|}
\hline Scientific name & Fraction & Conc. ( $\mu \mathrm{g} / \mathrm{ml})$ & Inhibition (\%) $)^{a}$ & $\mathrm{IC} \mathrm{C}_{50}(\mu \mathrm{g} / \mathrm{ml})$ \\
\hline \multirow[t]{20}{*}{ Polygonum cuspidatum } & Ethanol extract (POCU1) & 0 & $0 \pm 4.8$ & $72.5 \pm 6.7$ \\
\hline & & 50 & $45.8 \pm 1.9$ & \\
\hline & & 100 & $54.9 \pm 0.3$ & \\
\hline & & 150 & $62.7 \pm 3.2$ & \\
\hline & n-Hexane (POCU1h) & 0 & $0 \pm 4.8$ & $326.9 \pm 36.6$ \\
\hline & & 200 & $33.9 \pm 3.2$ & \\
\hline & & 300 & $44.7 \pm 7.3$ & \\
\hline & & 400 & $64.1 \pm 7.2$ & \\
\hline & Ethyl acetate (POCU1ea) & 0 & $0 \pm 4.8$ & $26.4 \pm 1.9$ \\
\hline & & 20 & $44.6 \pm 3.4$ & \\
\hline & & 30 & $52.5 \pm 0.7$ & \\
\hline & & 40 & $54.1 \pm 0.4$ & \\
\hline & n-Butanol (POCU1b) & 0 & $0 \pm 4.8$ & $15.8 \pm 2.6$ \\
\hline & & 10 & $46.5 \pm 0.3$ & \\
\hline & & 15 & $49.7 \pm 2.4$ & \\
\hline & & 20 & $52.8 \pm 1.4$ & \\
\hline & Water (POCU1w) & 0 & $0 \pm 4.8$ & $295.8 \pm 10.9$ \\
\hline & & 200 & $46.6 \pm 1.6$ & \\
\hline & & 300 & $50.1 \pm 0.2$ & \\
\hline & & 400 & $52.8 \pm 0.6$ & \\
\hline
\end{tabular}

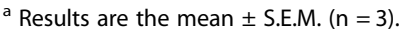




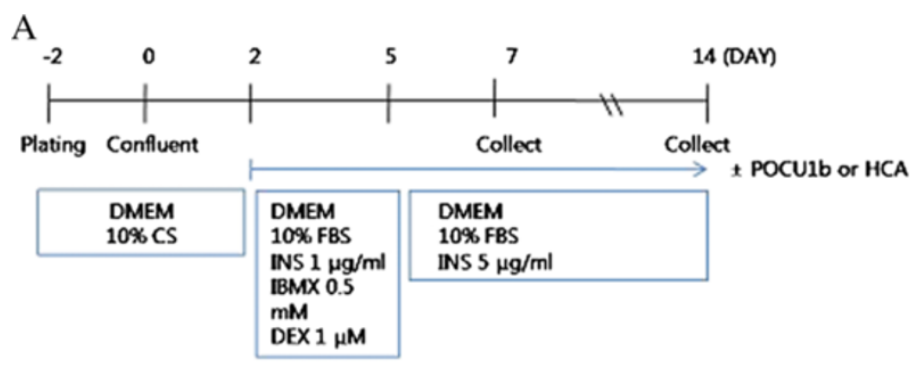

B

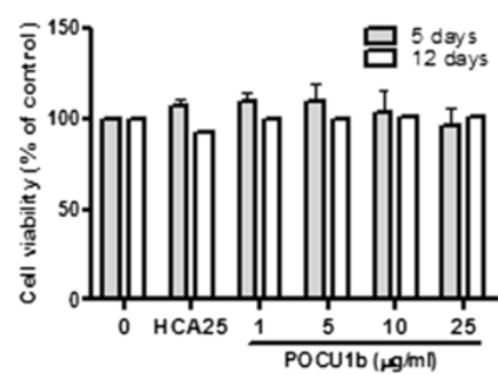

C

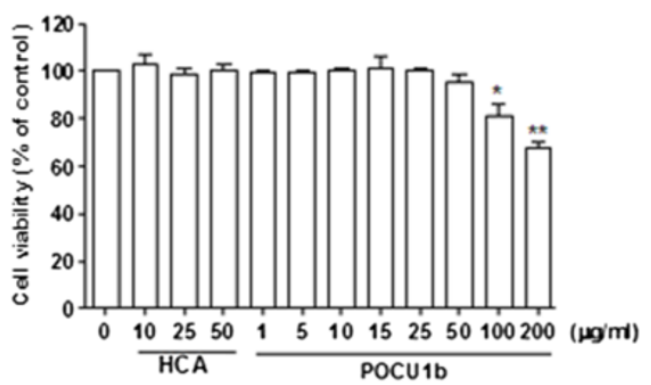

Figure 1 Cytotoxicity of POCU1b. (A) 3 T3-L1 differentiation. (B) Cytotoxicity of POCU1b using the CCK-8 kit. Cells were treated with different concentrations of POCU1b for 5 or 12 days. Data are expression as the mean \pm S.E.M. $(n=4)$. (C) Cytotoxicity at high concentrations of POCU1b. Cells were treated with high concentrations of POCU1b $(\sim 200 \mu \mathrm{g} / \mathrm{mL})$ for 12 days. Data are expression as the mean \pm S.E.M. $(n=6) .^{*} p<0.05$, ${ }^{* *} p<0.01$ vs. untreated cells.

stained very strongly with Oil red $\mathrm{O}$, an indication that the cells accumulated substantial amounts of cytoplasmic triglycerides. Representative images of Oil red $\mathrm{O}$ staining in treated cells showed that POCU1b suppressed both triglyceride accumulation and adipocyte differentiation in a dose-dependent manner (Figure 2A and $2 \mathrm{~B})$. HCA treatment of cells also reduced staining with Oil red $\mathrm{O}$, indicative of low triglyceride content.

Expression of GPDH is induced the conversion of preadipocytes to adipocytes [23]. We examined the effect of POCU1b on the activity of GPDH. POCU1b treatment of 3 T3-L1 adipocytes resulted in a marked decrease in $\mathrm{GPDH}$ activity in a dose-dependent manner (Figure 2C; POCU1b $25 \mu \mathrm{g} / \mathrm{ml}$ vs. control, $p<0.05)$.

\section{POCU1b phosphorylates AMP-activated protein kinase (AMPK)}

Several studies have suggested that AMPK acts as a major energy sensor and regulator in adipose tissues [24] and that activation of AMPK leads to lipid lowering [25]. To determine the effects of POCU1b on AMPK activation in 3 T3-L1 adipocytes, cells were treated with or without POCU1b and AMPK was detected by immunoblot analysis. Levels of pAMPK were markedly increased in a dose-dependent manner following POCU1b treatment (Figure 3). At a same dose $(25 \mu \mathrm{g} / \mathrm{ml})$, these resulted in a $78 \%$ increase for POCU1b and $17 \%$ increase for HCA.
Effect of POCU1b on expression of lipid accumulationrelated factors

ADRP stimulates lipid accumulation and lipid droplet formation [26]. Therefore, we tested the effects of POCU1b on the expression of ADRP, a lipid-associated protein that is expressed during early adipose differentiation. POCU1b reduced protein and mRNA expression levels of ADRP in a dose-dependent manner (Figure 4). Similar to ADRP, perilipin stimulated lipid accumulation and localized to the surfaces of lipid droplets $[27,28]$. As shown in Figure 4, perilipin protein (Figure 4A, middle panel) and mRNA (Figure 4B, middle panel) expression levels decreased in POCU1b-treated 3 T3-L1 adipocytes in a dose-dependent manner.

\section{Effect of POCU1b on mRNA and protein expression levels} of adipogenic factors

To determine whether suppression of both triglyceride accumulation and GPDH activity was caused by the inhibition of an adipogenic mechanism, we examined the expression levels of mRNA and protein of the adipogenic transcription factors PPAR- $\gamma$ and $\mathrm{C} /$ EBP- $\alpha$ in POCU1b-treated 3 T3-L1 adipocytes. As shown in Figure 5, POCU1b reduced both protein (Figure 5A, upper panel) and mRNA (Figure 5B, upper panel) expression levels of PPAR- $\gamma$ compared with standard differentiated adipocytes in a dosedependent manner. Both protein and mRNA expression 


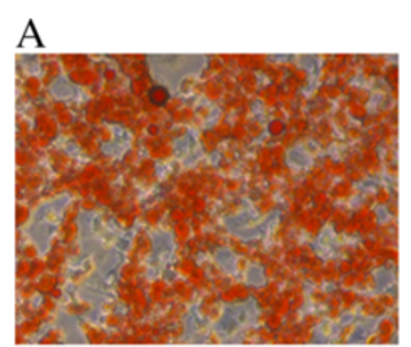

0

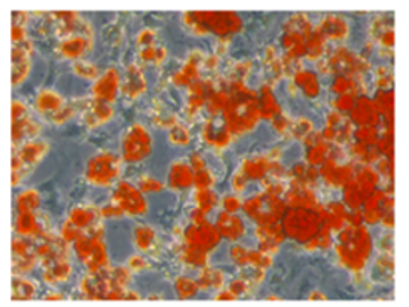

+POCU1b $(10 \mu \mathrm{g} / \mathrm{ml})$

B

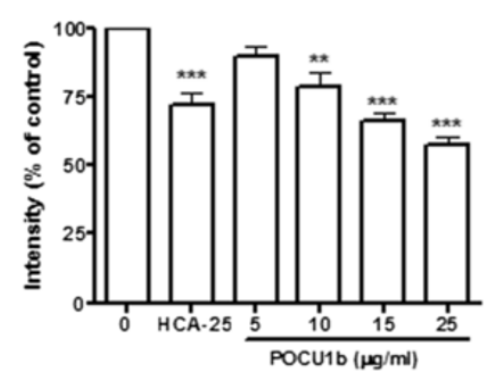

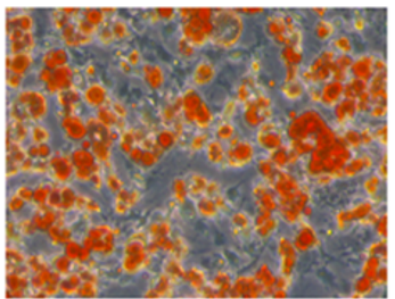

$+\mathrm{HCA}(25 \mu \mathrm{g} / \mathrm{ml})$

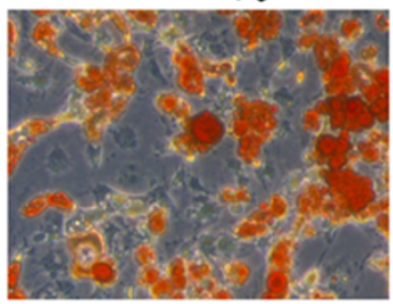

+POCU1b $(15 \mu \mathrm{g} / \mathrm{ml})$

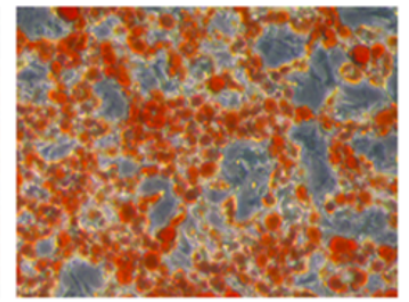

+POCU1b $(5 \mu \mathrm{g} / \mathrm{ml})$

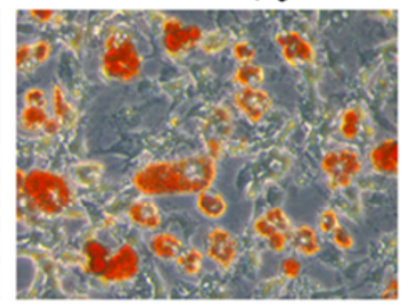

+POCU1b $(25 \mu \mathrm{g} / \mathrm{ml})$

$\mathrm{C}$

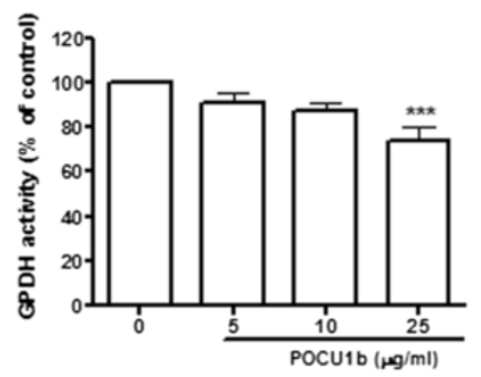

Figure 2 POCU1b inhibits adipocyte differentiation and GPDH activity. (A) Oil red O staining for lipid content in 3 T3-L1 adipocytes. 3 T3-L1 preadipocytes were induced to differentiate in POCU1b $(5-25 \mu \mathrm{g} / \mathrm{mL})$ for 12 days. (B) Relative density of Oil red O staining. Data are expressed as the mean \pm S.E.M. $(n=5) .{ }^{* *} p<0.01$, and ${ }^{* * *} p<0.001$ vs. untreated cells, respectively. (C) Confluent 3 T3-L1 preadipocytes were induced to differentiate in the presence or absence of POCU1b $(5,15$, or $25 \mu \mathrm{g} / \mathrm{mL})$. Cells were lysed on day 12 , and GPDH activity was measured. Data are expressed as means \pm S.E.M. $(n=5)$ for three independent experiments, normalized to GPDH activity obtained under standard differentiation conditions. ${ }^{* *} p<0.001$ vs. untreated cells.

levels of C/EBP- $\alpha$ were also decreased in a dosedependent manner in POCU1b-treated 3 T3-L1 cells (Figure 5A and B, middle panel). Thus, we conclude that POCU1b regulates the production of adipogenic transcription factors during the adipocyte differentiation process in $3 \mathrm{~T} 3-\mathrm{L} 1$ adipocytes.

\section{Discussion}

In the present study, POCU1b exhibited the strongest inhibitory effect on lipase activity and the putative antiobesity effects of POCU1b were investigated for the first time through the inhibition of adipocyte differentiation. POCU1b suppressed triglyceride accumulation in $3 \mathrm{~T} 3-\mathrm{L} 1$
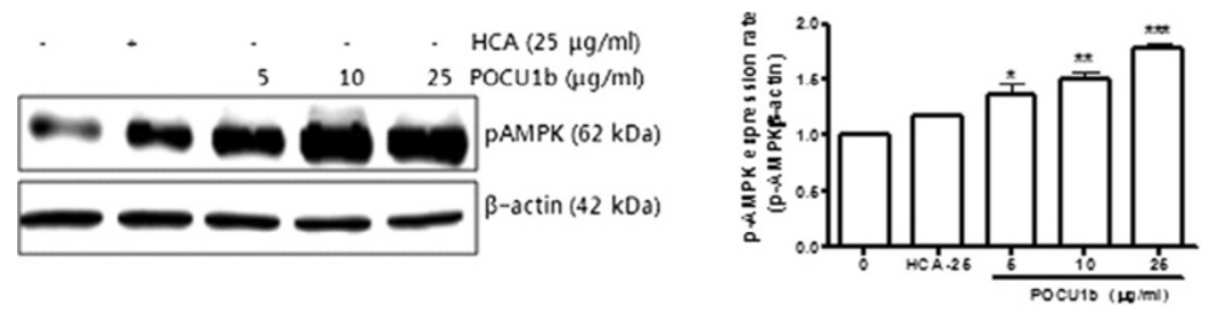

Figure 3 POCU1b activates AMPK signaling in a dose-dependent manner. Cells were collected after 12 days and lysed. AMPK activation was determined by immunoblot analysis. Data represent the mean \pm S.E.M. of at least three experiments performed in triplicate. ${ }^{*} p<0.05$, ${ }^{* *} p<0.01$, and ${ }^{* *} p<0.001$ vs. untreated cells, respectively. 


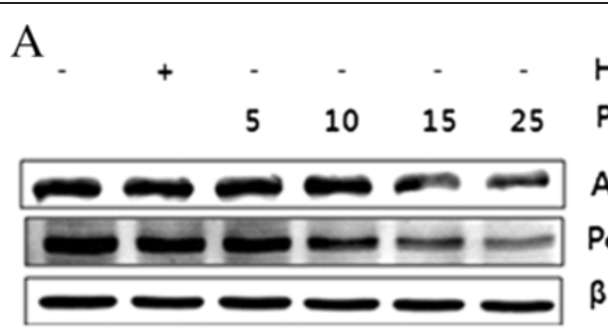

$\mathrm{HCA}(25 \mu \mathrm{g} / \mathrm{ml})$

POCU1b $(\mu \mathrm{g} / \mathrm{ml})$

ADRP (48 kDa)

Perilipin (57 kDa)

$\beta$-actin (42 kDa)
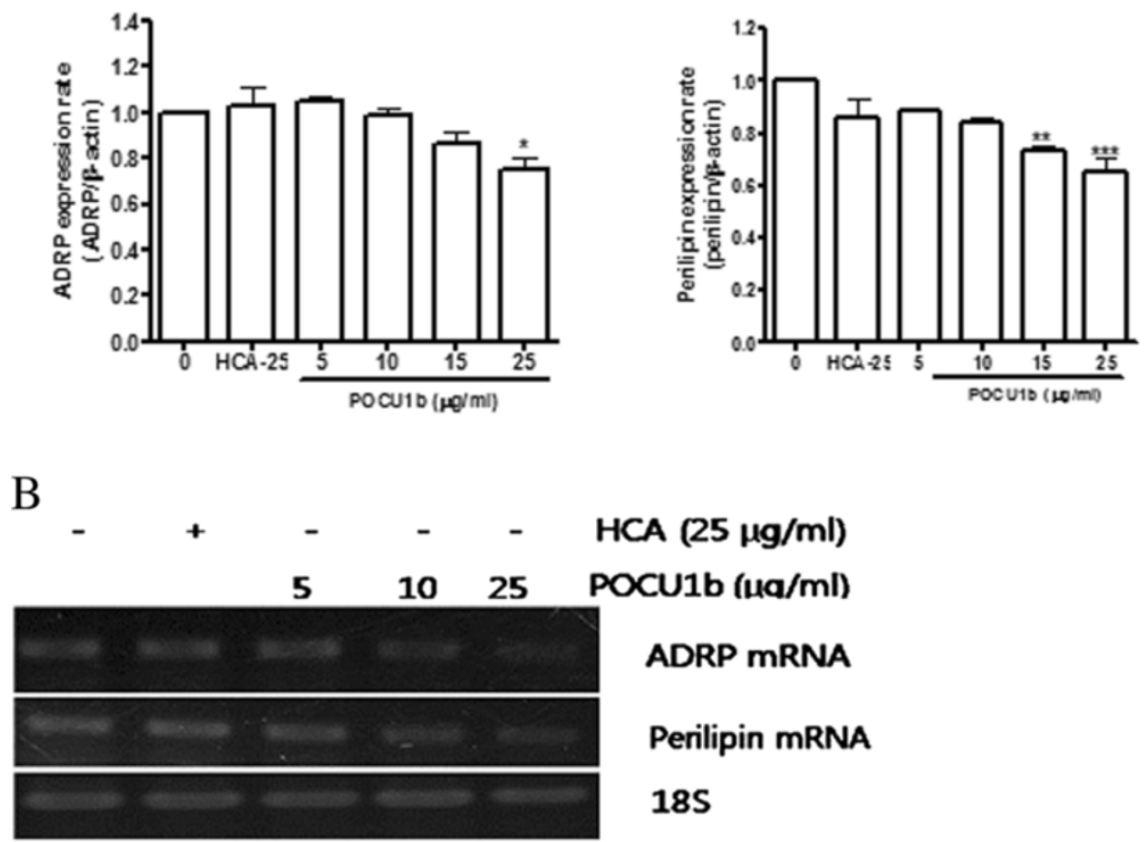

HCA $(25 \mu \mathrm{g} / \mathrm{ml})$

$\mathrm{POCU} 1 \mathrm{~b}(\mu \mathrm{a} / \mathrm{ml})$

ADRP MRNA

Perilipin mRNA

$18 \mathrm{~S}$
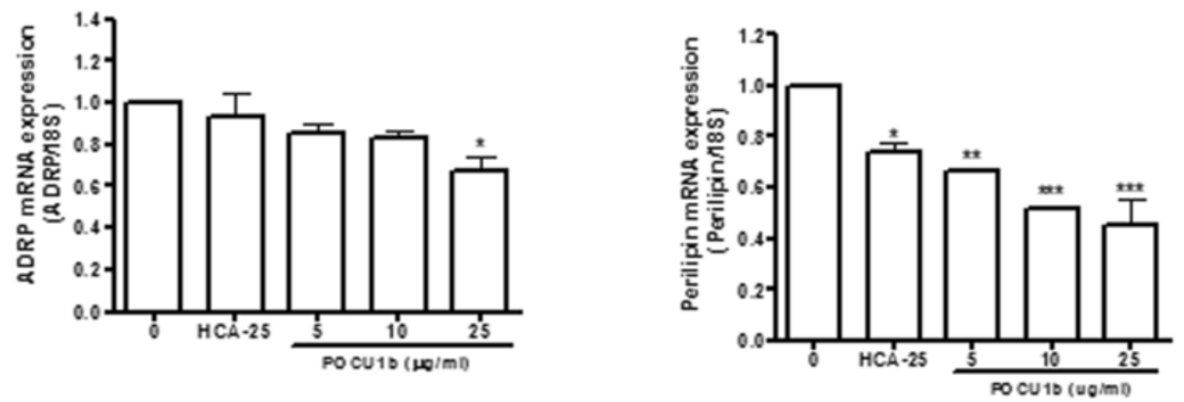

Figure 4 Effects of POCU1b on expression of ADRP and perilipin expression levels. (A) ADRP and perilipin protein levels were detected by immunoblot analysis and suppressed in a dose-dependent manner by POCU1b. Data represent the mean \pm SEM of at least three experiments performed in triplicate. ${ }^{*} p<0.05$, ${ }^{*} p<0.01$, and ${ }^{* *} p<0.001$ vs. untreated cells, respectively. (B) Expressions of ADRP and perilipin mRNA were analyzed by RT-PCR and suppressed in a dose-dependent manner by POCU1b. Data represent the mean \pm S.E.M. of at least three experiments performed in triplicate. ${ }^{*} p<0.05,{ }^{* *} p<0.01$, and ${ }^{* * *} p<0.001$ vs. untreated cells, respectively.

adipocytes. GPDH activity (a marker of adipocyte differentiation) was also significantly diminished by POCU1b in a dose-dependent manner, and pAMPK activity was markedly increased in 3 T3-L1 adipocytes. Furthermore, both ADRP and perilipin levels were decreased, and levels of the adipogenic transcription factors PPAR- $\gamma$ and $\mathrm{C} / \mathrm{EBP}-\alpha$ were also significantly decreased after POCU1b treatment. We also observed reduced lipid content in adipocytes, increased phosphorylation of AMPK, inhibition of lipid accumulation via lower ADRP and perilipin levels, and the inhibition of differentiation in 3 T3-L1 adipocytes.

Natural products have been commonly used as dietary supplements to control body weight $[13,14]$. P. cuspidatum has also been used as a natural laxative in traditional Asian herbal medicines [17]. In our study, the 

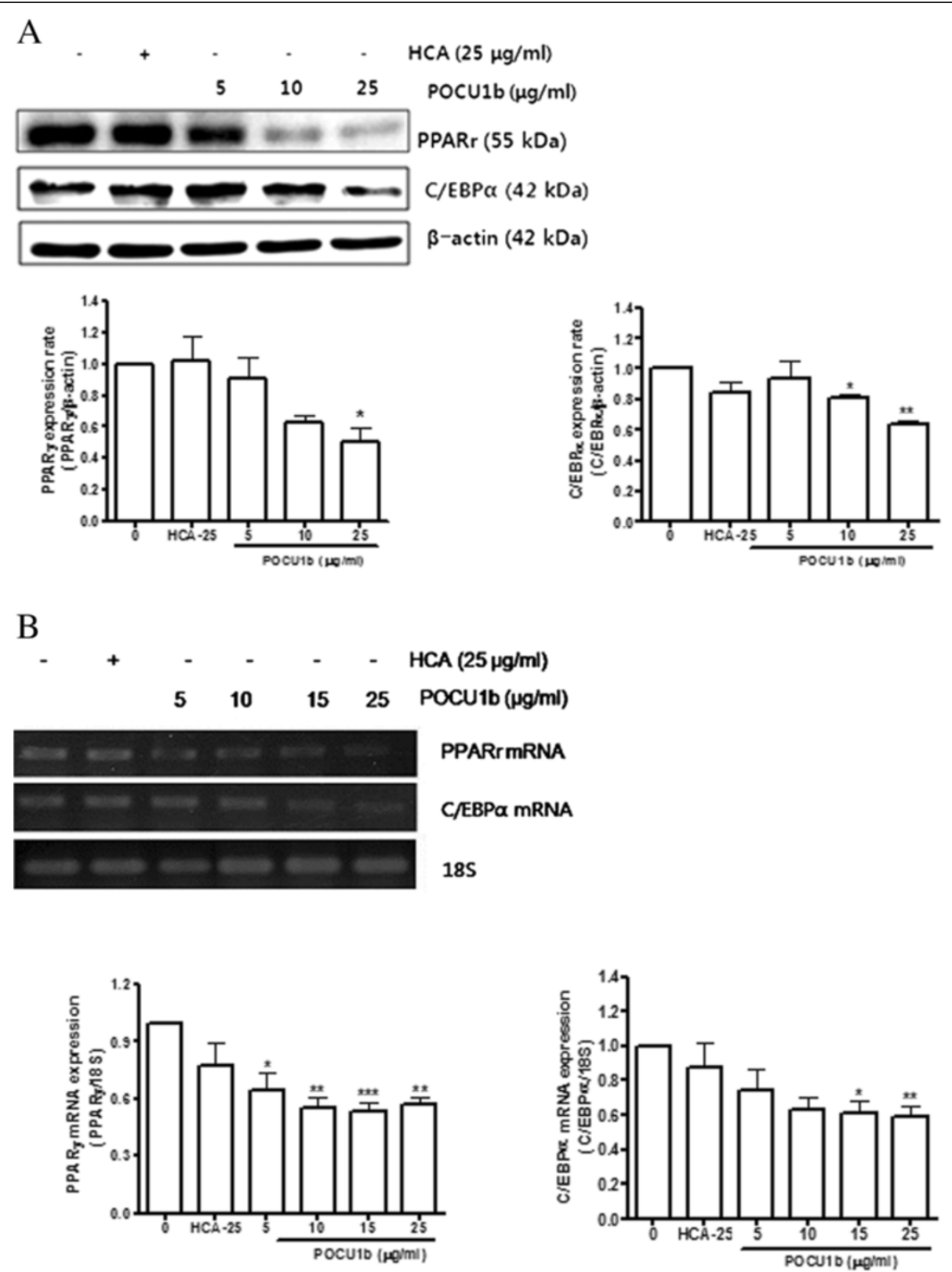

Figure 5 Effects of POCU1b PPAR- $\gamma$ and C/EBP- $a$ on protein and mRNA expression levels. (A) PPAR- $\gamma$ and C/EBP-a protein levels were detected by immunoblot analysis and suppressed in a dose-dependent manner by POCU1b. Data represent the mean \pm SEM of at least three experiments performed in triplicate. ${ }^{*} p<0.05$ and ${ }^{* *} p<0.01$ vs. untreated cells, respectively. (B) Expressions of PPAR- $\gamma$ and C/EBP-a mRNA were analyzed by RT-PCR. Data represent the mean \pm SEM of at least three experiments performed in triplicate. ${ }^{*} p<0.05,{ }^{* *} p<0.01$, and ${ }^{* * *} p<0.001$ vs. untreated cells, respectively.

ethanol extract of $P$. cuspidatum exhibited strong antilipase activity, with an $\mathrm{IC}_{50}$ value of $72.5 \pm 67 \mu \mathrm{g} / \mathrm{ml}$. Especially, POCU1b showed the strongest activity $\left(\mathrm{IC}_{50}=15.8 \pm 1.9 \mu \mathrm{g} / \mathrm{ml}\right)$. P. cuspidatum is composed of phytochemicals such as emodin and resveratrol $[17,29,30]$. The anti-diabetic effects of emodin and resveratrol have been studied both in vitro and in vivo $[12,31,32]$. A recent study showed that emodin exhibits a very high-binding affinity to PPAR- $\gamma$ and induces both a time- and dose-dependent increase in glucose uptake as well as in GLUT1 and GLUT4 mRNA expression levels in differentiated 3 T3-L1 adipocytes [33].

Adipocytes play a critical role in the regulation of energy balance. Adipose tissue growth involves an increase in adipocyte size and/or number. Changes in adipocyte number are achieved through a complex interplay between the proliferation and differentiation of preadipocytes. Adipocyte differentiation (adipogenesis) regulates 
the amount of white adipose tissue (WAT) mass [34]. In this study, POCU1b inhibited adipocyte differentiation in 3 T3-L1 cells in a dose-dependent manner. It is noteworthy that inhibition of adipocyte differentiation reduces adipocyte number in WAT, which acts as a secretory/ endocrine organ that mediates numerous physiological and pathological processes.

GPDH activity is high in mature adipocytes; the activity of this enzyme is therefore routinely measured to assess adipogenic differentiation in cultured cells [35] and has been used as an index for monitoring triglyceride synthesis [21]. In the current study, we found that treatment with POCU1b $(25 \mu \mathrm{g} / \mathrm{ml})$ suppressed GPDH activity without affecting cell viability. However, treatment with HCA, an active compound of Garcinia cambogia, had no significant effects on cells after 12 days (Data not shown). Hasegawa et al. showed consistently that GPDH activity was not significantly inhibited by treatment with Garcinia extract after 21 days. However, the accumulation of lipid droplets was inhibited [36]. AMPK is activated when cellular energy stores are depleted and accelerates ATP-generating catabolic pathways, including glucose and fatty acid oxidation, while reducing ATP-consuming anabolic pathways, including fatty acid and triacylglycerol synthesis [12]. POCU1b activated AMPK in a dose-dependent manner, suggesting that the reduction in energy storage and the increase in energy production occurred through a change in the intracellular ATP-to-AMP ratio (Figure 3).

Proteins on the surfaces of lipid droplets in adipocytes, especially ADRP and perilipin, serve as nucleation centers for the assembly of lipids into nascent lipid droplets [31,37]. Expression of ADRP and perilipin was also inhibited by POCU1b treatment in 3 T3-L1 adipocytes. POCU1b also blocked the expression of the adipogenic transcription factors C/EBP- $\alpha$ and PPAR $-\gamma$, shown to be important players in adipocyte differentiation. $\mathrm{C} / \mathrm{EBP}-\alpha$ knock-out $(\mathrm{C} / \mathrm{EBP} \alpha-/-)$ mice neither develop adipose tissue normally nor accumulate triglycerides, the hallmark of WAT, suggesting a central role for $\mathrm{C} / \mathrm{EBP}-\alpha$ in adipogenesis [38]. Additionally, PPAR- $\gamma$ is known to be a key protein that is expressed prior to $\mathrm{C} / \mathrm{EBP}-\alpha$ expression during early adipocyte differentiation of 3 T3-L1 cells [39].

\section{Conclusions}

The present study demonstrated that POCU1b blocks 3 T3-L1 adipocyte differentiation in a dose-dependent manner and inhibits the expression of the key transcription factors PPAR- $\gamma$ and C/EBP- $\alpha$. This study also showed that POCU1b treatment prevents the expression of ADRP and perilipin by both attenuating lipid accumulation and activating AMPK phosphorylation. Thus, POCU1b is worthwhile to further investigate for its potential pharmacological effect in metabolic disorders, specifically obesity.

\section{Additional file}

Additional file 1: Figure S1. POCU1 inhibits adipocyte differentiation Oil red $\mathrm{O}$ staining for lipid content in 3 T3-L1 adipocytes. 3 T3-L1 preadipocytes were induced to differentiate in extract $(25 \mu \mathrm{g} / \mathrm{mL})$ or fractions $(25 \mu \mathrm{g} / \mathrm{mL})$ for 12 days. POCU1, the ethanol extract of $P$. cuspidatum; POCU1h, n-hexane fraction of the ethanol extract of $P$. cuspidatum; POCU1ea, ethyl acetate fraction of the ethanol extract of $P$. cuspidatum; POCU1b, $\mathrm{n}$-butanol fraction of the ethanol extract of $P$. cuspidatum; POCU1w, Water fraction of the ethanol extract of $P$. cuspidatum.

\section{Competing interests}

The authors declare that they have no competing interests.

\section{Authors' contributions}

YSK and JSK: Designed the study and wrote the manuscript; YSK and YML: Carried out the cell culture experiments; JHK: Identification of plant. All authors read and approved the final manuscript.

\section{Acknowledgements}

This research was supported by grants from the Korea Research Council of Fundamental Science \& Technology (KRCF) [G08100] and the Korea Institute of Oriental Medicine (KIOM) grants [K11040 and K12040].

\section{Author details}

${ }^{1}$ Korean Medicine-Based Herbal Drug Development Group, Herbal Medicine Research Division, Korea Institute of Oriental Medicine (KIOM), Daejeon 305-811, Republic of Korea. 'Department of Life Science, Gachon University, Seongnam, Kyonggi-do 461-701, Republic of Korea.

Received: 10 July 2013 Accepted: 23 October 2013

Published: 25 October 2013

\section{References}

1. Bray GA, Lovejoy JC, Smith SR, DeLany JP, Lefevre M, Hwang D, Ryan DH, York DA: The influence of different fats and fatty acids on obesity, insulin resistance and inflammation. J Nutri 2002, 132:2488-2491.

2. Riccardi G, Giacco R, Rivellese AA: Dietary fat, insulin sensitivity and the metabolic syndrome. Clin Nutri 2004, 23:447-456.

3. Pantoja C, Huff JT, Yamamoto KR: Glucocorticoid signaling defines a novel commitment state during adipogenesis in vitro. Mol Biol Cell 2008, 19:4032-4041.

4. Roncari DA, Lau DC, Kindler S: Exaggerated replication in culture of adipocyte precursors from massively obese persons. Metabolism 1981 30:425-427.

5. Lin J, Della-Fera MA, Baile CA: Green tea polyphenol epigallocatechin gallate inhibits adipogenesis and induces apoptosis in 3T3-L1 adipocytes. Obesity Rse 2005, 13:982-990.

6. Yang JY, Della-Fera MA, Rayalam S, Ambati S, Hartzell DL, Park HJ, Baile CA Enhanced inhibition of adipogenesis and induction of apoptosis in 3T3-L1 adipocytes with combinations of resveratrol and quercetin. Life Sci 2008, 82(19-20):1032-1039.

7. Furuyashiki T, Nagayasu H, Aoki Y, Bessho H, Hashimoto T, Kanazawa K, Ashida $\mathrm{H}$ : Tea catechin suppresses adipocyte differentiation accompanied by down-regulation of PPARgamma2 and C/EPalpha in 3T3-L1 cells. Biosci Biotech Bioch 2004, 68:2353-2359.

8. He ML, Wang Y, You JS, Mir PS, McAllister TA: Effect of a seaweed extract on fatty acid accumulation and glycerol-3-phosphate dehydrogenase activity in 3T3-L1 adipocytes. Lipids 2009, 44:125-132.

9. Rayalam S, Yang JY, Ambati S, Della-Fera MA, Baile CA: Resveratrol induces apoptosis and inhibits adipogenesis in 3T3-L1 adipocytes. Phytother Res 2008, 22:1367-1371.

10. Park HJ, Yang JY, Ambati S, Della-Fera MA, Hausman DB, Rayalam S, Baile CA: Combined effects of genistein, quercetin, and resveratrol in human and 3T3-L1 adipocytes. J Med Food 2008, 11:773-783. 
11. Lee YS, Kim WS, Kim KH, Yoon MJ, Cho HJ, Shen Y, Ye JM, Lee CH, Oh WK, Kim CT, Hohnen-Behrens C, Gosby A, Kraegen EW, Jame s DE, Kim JB: Berberine, a natural plant product, activates AMP-activated protein kinase with beneficial metabolic effects in diabetic and insulin-resistant states. Diabetes 2006, 55:2256-2264.

12. Park CE, Kim MJ, Lee JH, Min BI, Bae H, Choe W, Kim SS, Ha J: Resveratrol stimulates glucose transport in $\mathrm{C} 2 \mathrm{C} 12$ myotubes by activating AMP-activated protein kinase. Experi Mol Med 2007, 39:222-229.

13. Preuss HG, Rao CV, Garis R, Bramble JD, Ohia SE, Bagchi M, Bagchi D: An overview of the safety and efficacy of a novel, natural (-)-hydroxycitric acid extract (HCA-SX) for weight management J Med 2004, 35:33-48.

14. Birari RB, Bhutani KK: Pancreatic lipase inhibitors from natural sources: unexplored potential. Drug Discov Today 2007, 12:879-889.

15. Torgerson JS, Hauptman J, Boldrin MN, Sjostrom L: XENical in the prevention of diabetes in obese subjects (XENDOS) study: a randomized study of orlistat as an adjunct to lifestyle changes for the prevention of type 2 diabetes in obese patients. Diabetes care 2004, 27:155-161.

16. Bray GA: Medications for obesity: mechanisms and applications. Clin Chest Med 2009, 30:525-538.

17. Park CS, Lee YC, Kim JD, Kim HM, Kim CH: Inhibitory effects of Polygonum cuspidatum water extract (PCWE) and its component resveratrol [correction of rasveratrol] on acyl-coenzyme A-cholesterol acyltransferase activity for cholesteryl ester synthesis in HepG2 cells. Vascul Pharmacol 2004, 40:279-284.

18. Kim YS, Lee YM, Kim H, Kim J, Jang DS, Kim JH, Kim JS: Anti-obesity effect of Morus bombycis root extract: anti-lipase activity and lipolytic effect. J Ethnopharmacol 2010, 130:621-624.

19. Kim YS, Lee YM, Kim J, Sohn E, Kim C-H, Lee YM, Jo K, Shin S, Song Y, Kim JH, Kim JS: Inhibitory Activities of Cudrania tricuspidata Leaves on Pancreatic Lipase In Vitro and Lipolysis In Vivo. eCAM 2012(Article ID 878365):8. doi:10.1155/2012/878365. http://www.ncbi.nlm.nih.gov/pubmed/? term $=23365603$

20. Kozak LP, Jensen JT: Genetic and developmental control of multiple forms of L-glycerol 3-phosphate dehydrogenase. J Biol Chem 1974, 249:7775-7781.

21. Wise LS, Green H: Participation of one isozyme of cytosolic glycerophosphate dehydrogenase in the adipose conversion of 3T3 cells. J Biol Chem 1979, 254:273-275.

22. Kim YS, Jung DH, Kim NH, Lee YM, Kim JS: Effect of magnolol on TGF-beta1 and fibronectin expression in human retinal pigment epithelial cells under diabetic conditions. Eur J Pharm 2007, 562:12-19.

23. Tomiyama K, Nakata H, Sasa H, Arimura S, Nishio E, Watanabe Y: Wortmannin, a specific phosphatidylinositol 3-kinase inhibitor, inhibits adipocytic differentiation of 3T3-L1 cells. BBRC 1995, 212:263-269.

24. An Z, Wang H, Song P, Zhang M, Geng X, Zou MH: Nicotine-induced activation of AMP-activated protein kinase inhibits fatty acid synthase in 3T3L1 adipocytes: a role for oxidant stress. J Biol Chem 2007, 282:26793-26801.

25. Zang M, Zuccollo A, Hou X, Nagata D, Walsh K, Herscovitz H, Brecher P, Ruderman NB, Cohen RA: AMP-activated protein kinase is required for the lipid-lowering effect of metformin in insulin-resistant human HepG2 cells. J Biol Chem 2004, 279:47898-47905.

26. Imamura M, Noguchi TI, Ikuyama S, Taniguchi S, Kobayashi K, Nakashima N, Nawata H: ADRP stimulates lipid accumulation and lipid droplet formation in murine fibroblasts. Am J Physiol End Metabol 2002, 283:E775-E783.

27. Blanchette-Mackie EJ, Dwyer NK, Barber T, Coxey RA, Takeda T, Rondinone CM, Theodorakis JL, Greenberg AS, Londos C: Perilipin is located on the surface layer of intracellular lipid droplets in adipocytes. J Lipid Res 1995, 36:1211-1226.

28. Brasaemle DL, Rubin B, Harten IA, Gruia-Gray J, Kimmel AR, Londos C: Perilipin A increases triacylglycerol storage by decreasing the rate of triacylglycerol hydrolysis. J Biol Chem 2000, 275:38486-38493.

29. Wang SM, Hwang RD, Greenberg AS, Yeo HL: Temporal and spatial assembly of lipid droplet-associated proteins in 3T3-L1 preadipocytes. Histochem Cell Biol 2003, 120:285-292.

30. Zhuang $X$, Dong $X, M a$ S, Zhang T: Selective on-line extraction of transresveratrol and emodin from Polygonum cuspidatum using molecularly imprinted polymer. J Chrom Sci 2008, 46:739-742.
31. Wang J, Huang H, Liu P, Tang F, Qin J, Huang W, Chen F, Guo F, Liu W, Yang B: Inhibition of phosphorylation of p38 MAPK involved in the protection of nephropathy by emodin in diabetic rats. Eur J Pharmacol 2006, 553:297-303.

32. Xue J, Ding W, Liu Y: Anti-diabetic effects of emodin involved in the activation of PPARgamma on high-fat diet-fed and low dose of streptozotocin-induced diabetic mice. Fitoterapia 2010, 91:173-177.

33. Yang $Y$, Shang $W$, Zhou $L$, Jiang $B$, Jin $H$, Chen M: Emodin with PPARgamma ligand-binding activity promotes adipocyte differentiation and increases glucose uptake in 3T3-LI cells. BBRC 2007, 353:225-230.

34. Gregoire FM: Adipocyte differentiation: from fibroblast to endocrine cell. Exp Biol Med (Maywood) 2001, 226:997-1002.

35. Sottile $V$, Seuwen $\mathrm{K}$ : A high-capacity screen for adipogenic differentiation. Anal Biochem 2001, 293:124-128.

36. Hasegawa N: Garcinia extract inhibits lipid droplet accumulation without affecting adipose conversion in 3T3-L1 cells. Phytoth Res 2001 15:172-173.

37. Brasaemle DL, Barber T, Wolins NE, Serrero G, Blanchette-Mackie EJ, Londos C: Adipose differentiation-related protein is an ubiquitously expressed lipid storage droplet-associated protein. J Llipid Res 1997, 38:2249-2263.

38. Linhart HG, Ishimura-Oka K, DeMayo F, Kibe T, Repka D, Poindexter B, Bick RJ, Darlington GJ: C/EBPalpha is required for differentiation of white, but not brown, adipose tissue. PNAS USA 2001, 98:12532-12537.

39. Tontonoz P, Hu E, Graves RA, Budavari Al, Spiegelman BM: mPPAR gamma 2: tissue-specific regulator of an adipocyte enhancer. Genes \& Devel 1994 8:1224-1234.

doi:10.1186/1472-6882-13-282

Cite this article as: Kim et al:: Polygonum cuspidatum inhibits pancreatic lipase activity and adipogenesis via attenuation of lipid accumulation. BMC Complementary and Alternative Medicine 2013 13:282.

\section{Submit your next manuscript to BioMed Central and take full advantage of:}

- Convenient online submission

- Thorough peer review

- No space constraints or color figure charges

- Immediate publication on acceptance

- Inclusion in PubMed, CAS, Scopus and Google Scholar

- Research which is freely available for redistribution 